\title{
Psoriasis Area and Severity Index Clinical Classification
}

National Cancer Institute

\section{Source}

National Cancer Institute. Psoriasis Area and Severity Index Clinical Classification. NCI

Thesaurus. Code C135734.

A standardized survey developed by Fredriksson and Pettersson in 1978 to calculate the intensity and extent of psoriatic plaques before, during, and after retinoid treatment in chronic plaquetype psoriasis. The instrument utilizes a 5-point rating scale to measure intensity and assigns a numerical score for the percentage of anatomical involvement. 